\title{
Sistem Kendali PID pada Modus Transisi Terbang Tiltrotor
}

\author{
Syafrizal Akhzan*1, Andi Dharmawan ${ }^{2}$ \\ ${ }^{1}$ Program Studi Elektronika dan Instrumentasi, FMIPA UGM, Yogyakarta \\ ${ }^{2}$ Jurusan Ilmu Komputer dan Elektronika, FMIPA UGM, Yogyakarta \\ e-mail: *11 rizal.akhzan@gmail.com, ${ }^{2}$ dharmawan@ugm.ac.id
}

\begin{abstract}
Abstrak
Tiltrotor merupakan jenis pesawat tanpa awak yang dapat lepas landas secara vertikal dan terbang maju dengan kecepatan penuh. Kemampuan ini didukung dengan adanya aktuator yang dapat mengubah sudut baling-baling pada modus transisi. Tanpa adanya sistem kendali pada modus hovering dan transisi, akan menyebabkan tiltrotor sulit untuk dikendalikan. Penelitian ini bertujuan merancang dan membuat sistem yang mampu menstabilkan tiltrotor dengan mempertahankan sudut orientasi roll, pitch, dan yaw tiltrotor pada modus hovering dan transisi menggunakan pengendali PID.

Pengendali PID menggunakan negative feedback yang berasal dari pembacaan sensor accelerometer, gyroscope, dan magnetometer dengan metode DMP dan Madgwick quaternion menghasilkan keluaran pulsa untuk mengendalikan kecepatan motor brushless dan posisi sudut motor servo. Hasil dari pengendali PID juga dibandingkan dengan pengendali P dan PI.

Sesuai dengan pengujian, sistem kendali pada modus transisi pada sudut roll dengan setpoint $0^{\circ}$ mampu mempertahankan posisi sudut roll pada sudut rata-rata $0.48^{\circ}$ dengan standar deviasi $1.75^{\circ}$, pada sudut pitch dengan setpoint $-25^{\circ}$ mampu mempertahankan posisi sudut pitch pada sudut rata-rata $-25.26^{\circ}$ dengan standar deviasi $2.87^{\circ}$, pada sudut yaw mampu mempertahankan posisi sudut yaw pada rentang $-10^{\circ}$ hingga $0^{\circ}$ dengan sudut rata-rata $-3.78^{\circ}$ dan standar deviasi $1.83^{\circ}$.
\end{abstract}

Kata kunci-tiltrotor, PID, modus transisi

\section{Abstract}

Tiltrotor is an unmanned aerial vehicle which can take off vertically and fly with full speed. These abilities are supported by actuators, which can change the angle of propellers in transition mode. Without control system in hovering mode and transition mode, it will be difficult to control tiltrotor. The purpose of this research is to design the system which can stabilize the tiltrotor by maintaining oriented angle of tiltrotor's roll, pitch, and yaw in hovering mode and transition mode using PID controller.

PID controller uses negative feedback which is obtained from accelerometer, gyroscope, and magnetometer by using DMP method and Madgwick quaternion to produce the pulse to control the velocity of brushless motor and angle position of servo motor. The result of PID controller is also compared to P controller and PI controller.

According to the test, control system in transition mode for roll angle with setpoint $0^{\circ}$ is capable to maintain roll angle at average angle $0.48^{\circ}$ with standard deviation $1.75^{\circ}$, for pitch angle with setpoint $-25^{\circ}$ is capable to maintain pitch angle at average angle $-25.26^{\circ}$ with standard deviation $2.87^{\circ}$, for yaw angle is capable to maintain yaw angle at range $-10^{\circ}$ to $0^{\circ}$ with average angle $-3.78^{\circ}$ and standard deviation $1.83^{\circ}$.

Keywords-tiltrotor, PID, transition mode 


\section{PENDAHULUAN}

$\mathrm{P}$ esawat tanpa awak atau Unmanned Aerial Vehicle (UAV) kini menjadi suatu kebutuhan di dalam kehidupan untuk berbagai tujuan dan fungsi salah satunya adalah tiltrotor. Tiltrotor memiliki 3 modus penerbangan yaitu modus hovering, modus transisi, dan modus terbang maju. Kelebihan dari sistem ini adalah kemampuan terbang dengan kecepatan yang baik sehingga dapat menjangkau jarak yang jauh, dapat melayang di area tertentu, dan dapat lepas landas ataupun mendarat pada area yang terbatas.

Dengan kelebihan-kelebihan tersebut, tanpa adanya sistem kendali yang baik pada tiltrotor maka tiltrotor akan sangat sulit untuk dikendalikan. Sistem kendali yang baik disini adalah mampu untuk mempertahankan sudut orientasi tiltrotor pada $0^{\circ}$ pada modus hovering tiltrotor. Kestabilan pada modus hovering akan mempengaruhi tiltrotor ketika memasuki modus transisi. Modus transisi berperan penting agar tiltrotor dapat berpindah dari modus hovering menuju modus terbang maju. Tanpa adanya sistem kendali pada modus transisi maka sistem tidak akan dapat menjaga keseimbangannya ketika memasuki modus transisi dimana terjadi perubahan pergerakan servo yang dapat mengubah sudut orientasi menjauh dari setpoint-nya. Beberapa jenis metode kendali telah banyak diperkenalkan untuk pengendalian pesawat tanpa awak misalnya pengendali P, PI, dan PID. Sistem kendali tersebut memiliki keunggulan tersendiri pada setiap masing-masing sistem sesuai dengan karakteristik sistem itu sendiri.

Berdasarkan pemaparan di atas maka dibutuhkan sistem kendali untuk modus hovering dan modus transisi tiltrotor menggunakan sistem kendali P, PI, atau PID berdasarkan pengujian yang paling baik untuk tiltrotor.

\section{METODE PENELITIAN}

\subsection{Analisis Sistem}

Dalam penggunaan pengendali P, PI, dan PID pada sistem, perlu dilakukan tuning untuk menentukan konstanta P, I, dan D yang akan diterapkan pada sistem. Metode tuning yang digunakan dalam penelitian ini adalah classical tuning Ziegler-Nichols metode osilasi. Tuning menggunakan metode ini dilakukan secara eksperimental dengan memasukkan nilai Kp atau konstanta $\mathrm{P}$ hingga sistem berosilasi. Nilai tersebut kemudian menjadi ultimate gain $(\mathrm{Ku})$. Nilai konstanta $\mathrm{P}$ yang diterapkan pada sistem kemudian diambil dari persamaan Ziegler Nichols yang melibatkan ultimate gain tersebut. Sedangkan nilai konstanta I dan D dianalisa dari periode satu gelombang osilasi $(\mathrm{Pu})$ yang dihasilkan sistem namun juga tetap melibatkan pengaruh nilai ultimate gain. Dengan metode tuning PID yang seperti ini, tidak diperlukan analisa pemodelan sistem untuk tiltrotor. Persamaan sistem kendali PID Ziegler Nichols [1] ditunjukkan pada persamaan (1) dengan penentuan konstanta ditentukan dengan mengacu pada Tabel 1.

$$
\mathrm{G}_{\mathrm{c}}(\mathrm{s})=\mathrm{K}_{\mathrm{p}}\left(1+\frac{1}{T_{\mathrm{i}} s}+\mathrm{T}_{\mathrm{d}} \mathrm{s}\right)
$$

Tabel 1 Model penalaan konstanta PID dengan metode Ziegler-Nichols metode osilasi [1]

\begin{tabular}{|c|c|c|c|}
\hline Tipe Pengendali & $\mathrm{Kp}$ & $\mathrm{Ti}$ & $\mathrm{Td}$ \\
\hline $\mathrm{P}$ & $0,5 \mathrm{Ku}$ & 0 & - \\
\hline $\mathrm{PI}$ & $0,45 \mathrm{Ku}$ & $\mathrm{Pu} / 1,2$ & - \\
\hline PID & $0,6 \mathrm{Ku}$ & $0,5 \mathrm{Pu}$ & $0,125 \mathrm{Pu}$ \\
\hline
\end{tabular}

Dengan mengacu pada Tabel 1 maka $\mathrm{K}_{\mathrm{u}}$ (ultimate gain) dan $\mathrm{P}_{\mathrm{u}}$ (periode gelombang osilasi) dapat disubstitusikan ke dalam persamaan (2) menghasilkan persamaa (3).

$$
\mathrm{G}_{\mathrm{c}}(\mathrm{s})=0.6 \mathrm{~K}_{\mathrm{u}}\left(1+\frac{1}{0.5 P_{\mathrm{u}} s}+0.125 \mathrm{P}_{\mathrm{u}} \mathrm{s}\right)
$$




$$
\mathrm{G}_{\mathrm{c}}(\mathrm{s})=0.6 \mathrm{~K}_{\mathrm{u}}+\frac{0.6 K_{u}}{0.5 P_{\mathrm{u}} s}+0.075 \mathrm{~K}_{\mathrm{u}} \mathrm{P}_{\mathrm{u}} \mathrm{s}
$$

Persamaan $G_{c}$ (s) dapat diubah ke dalam suatu persamaan $K_{p}, K_{i}$, dan $K_{d}$ [2] yang dinyatakan dengan persamaan (4).

$$
\mathrm{G}_{\mathrm{c}}(\mathrm{s})=\mathrm{K}_{\mathrm{p}}+\frac{K_{\tilde{\mathrm{i}}}}{s}+\mathrm{K}_{\mathrm{d}} \mathrm{s}
$$

Melihat persamaan 4 maka didapat hubungan-hubungan antara $K_{p}, K_{i}$, dan $K_{d}$ dengan $K_{u}$ dan $\mathrm{P}_{\mathrm{u}}$ menghasilkan persamaan (5), (6), dan (7).

$$
\begin{gathered}
\mathrm{K}_{\mathrm{p}}=0.6 \mathrm{~K}_{\mathrm{u}} \\
\mathrm{K}_{\mathrm{i}}=\frac{0.6 K_{\mathrm{u}}}{0.5 P_{\mathrm{u}}} \\
\mathrm{K}_{\mathrm{d}}=0.075 \mathrm{~K}_{\mathrm{u}} \mathrm{P}_{\mathrm{u}}
\end{gathered}
$$

Dari nilai $K_{p}, K_{i}$, dan $K_{d}$ yang telah didapatkan dari persamaan di atas kemudian diterapkan pada persamaan pengendali PID pada ranah waktu yang bergantung pada besarnya error pada sistem saat ini, integral dari error pada interval waktu saat ini, dan derivatif dari sinyal error yang akan menetukan seberapa besar koreksi yang akan diterapkan terhadap sistem. Persamaan keluaran kontroler PID dituliskan pada persamaan (8).

$$
u(t)=K_{p} e(t)+K_{i} \int_{0}^{t} e(\tau) d(\tau)+K_{d} \frac{d e(t)}{d(t)}
$$

Keseimbangan dari tiltrotor diindikasikan dari nilai sudut orientasi yang terdiri dari roll, pitch, dan yaw. Sudut roll $(\phi)$ merupakan perputaran terhadap sumbu X bumi, sudut pitch $(\theta)$ merupakan perputaran terhadap sumbu Y bumi, dan sudut yaw $(\psi)$ merupakan perputaran terhadap sudut $\mathrm{Z}$ bumi. Sistem kendali akan menjaga tiltrotor pada setpoint yang ditentukan dengan parameter sudut orientasi baik pada modus hovering maupun transisi.

Skenario dari sistem kendali pada tiltrotor ditampilkan pada Gambar 1. Dimulai ketika tiltrotor memasuki modus hovering, sistem kendali yang akan mengatur kecepatan motor brushless dan motor servo untuk menjaga keseimbangan tiltrotor. Perpindahan dari modus hovering menuju modus transisi juga diatur oleh sistem kendali dengan mengubah sudut servo sebesar $20^{\circ}$. Modus transisi akan dijalankan pada 90 detik setelah tiltrotor memulai modus hovering. Sistem kendali akan mengatur keseimbangan ketika tiltrotor memasuki modus transisi. Kemudian tiltrotor akan mendarat dengan mengubah sudut servo kembali tegak lurus dengann tiltrotor serta kecepatan motor brushless dikurangi secara berkala hingga motor brushless berhenti berputar.

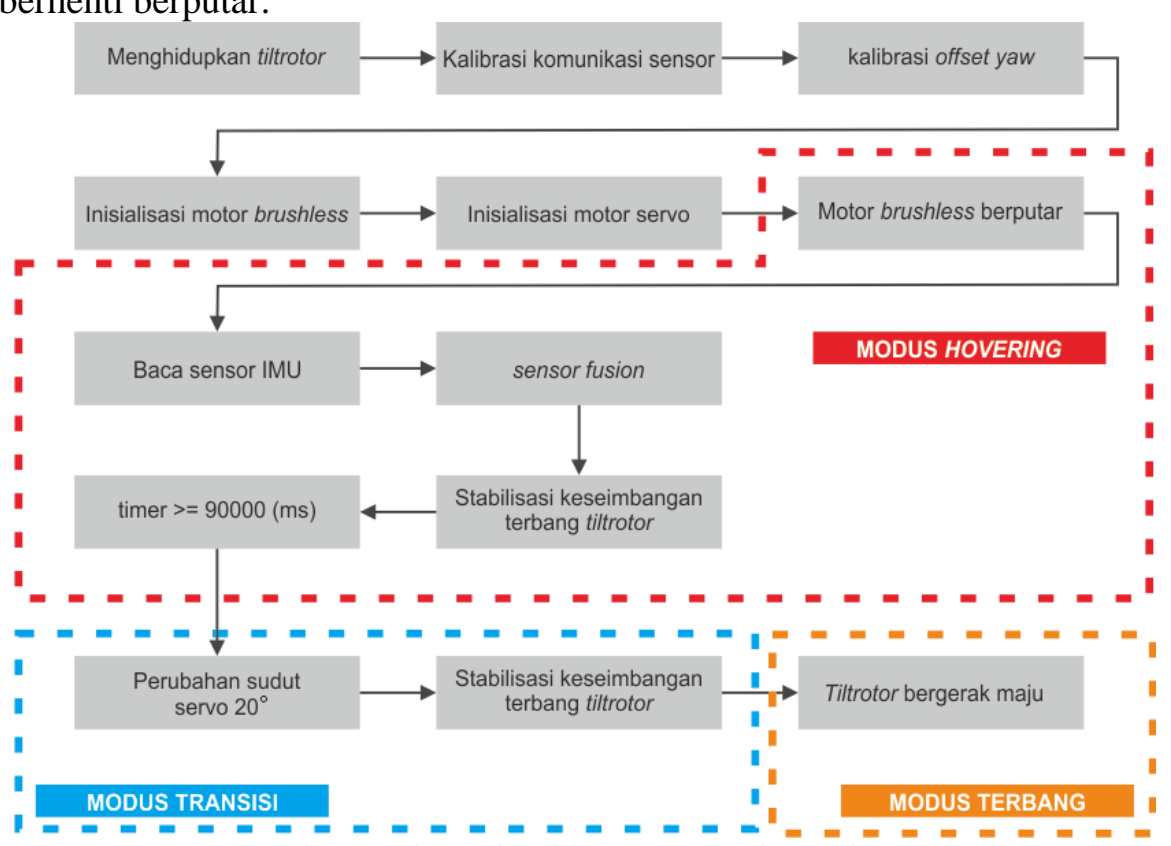

Gambar 1 Skenario sistem pergerakan tiltrotor 


\subsection{Arsitektur Sistem}

Tiltrotor yang akan dirancang dalam penelitian ini menggunakan beberapa sensor dan aktuator. Sensor yang digunakan adalah 9 DOF IMU yang terdiri dari sensor accelerometer, gyroscope, dan magnetometer. Sensor IMU berkomunikasi dengan mikrokontroler menggunakan jalur data I2C yang menggunakan pin SDA (Serial Data), SCL (Serial Clock), dan interrupt. Aktuator yang digunakan adalah motor brushless pada kedua sisi sayap tiltrotor sebagai tenaga penggerak yang dikendalikan menggunakan Electronic Speed Controller (ESC) dan motor servo sebagai pengatur derajat dari posisi motor brushless yang berpengaruh pada modus dari tiltrotor yaitu modus hovering atau modus terbang maju. Pengambilan data sudut orientasi dari tiltrotor diambil menggunakan YS-1020 menggunakan komunikasi serial dengan pin RX dan TX pada mikrokontroler. Seluruh kerja sensor dan aktuator dikendalikan oleh mikrokontroler. Arsitektur sistem secara keseluruhan terangkum pada diagram blok yang tampak pada Gambar 2.

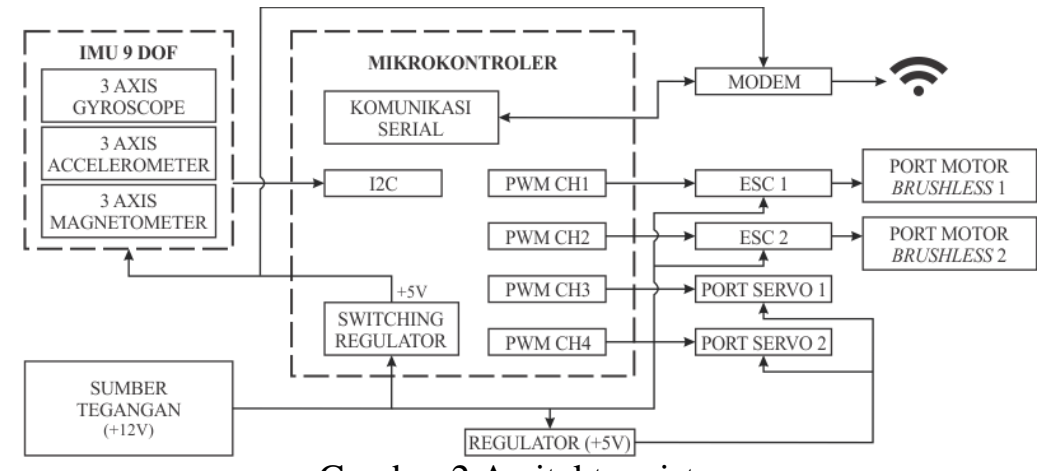

\subsection{Rancangan Sistem Kendali}

Gambar 2 Arsitektur sistem

Sistem kendali pada transisi terbang tiltrotor dikendalikan menggunakan pergerakan pitch (pada sumbu y) tiltrotor yaitu dengan mengubah sudut dari kedua baling-baling dengan menggunakan motor servo secara bersamaan. Posisi baling-baling diatur pada sudut tertentu yaitu condong ke depan yang menyebabkan tiltrotor akan memasuki modus fixed-wing sehingga dapat terbang maju. Dalam sistem ini, sensor accelerometer dan gyroscope akan membaca kemiringan tiltrotor pada sumbu $\mathrm{x}$ dan sumbu y yang kemudian hasil pembacaannya dikirimkan ke mikrokontroler. Nilai referensi telah ditetapkan sebelumnya sebagai nilai setpoint dimana jika terdapat selisih (error) antara nilai setpoint tersebut dengan hasil pembacaan nilai kemiringan oleh sensor maka mengindikasikan kestabilan dari tiltrotor sedang terganggu sehingga pengendali PID akan mengolah selisih (error) nilai kemiringan sehingga diperoleh hasil (output) yang diharapkan. Hasil yang dipengaruhi oleh pengendali PID berupa kecepatan putaran dari baling-baling tiltrotor dan posisi sudut servo yang mempengaruhi posisi sudut baling-baling sehingga dapat mengembalikan tiltrotor pada keadaan yang lebih stabil. Rancangan sistem kendali PID pada transisi terbang tiltrotor dapat ditunjukkan pada Gambar 3.

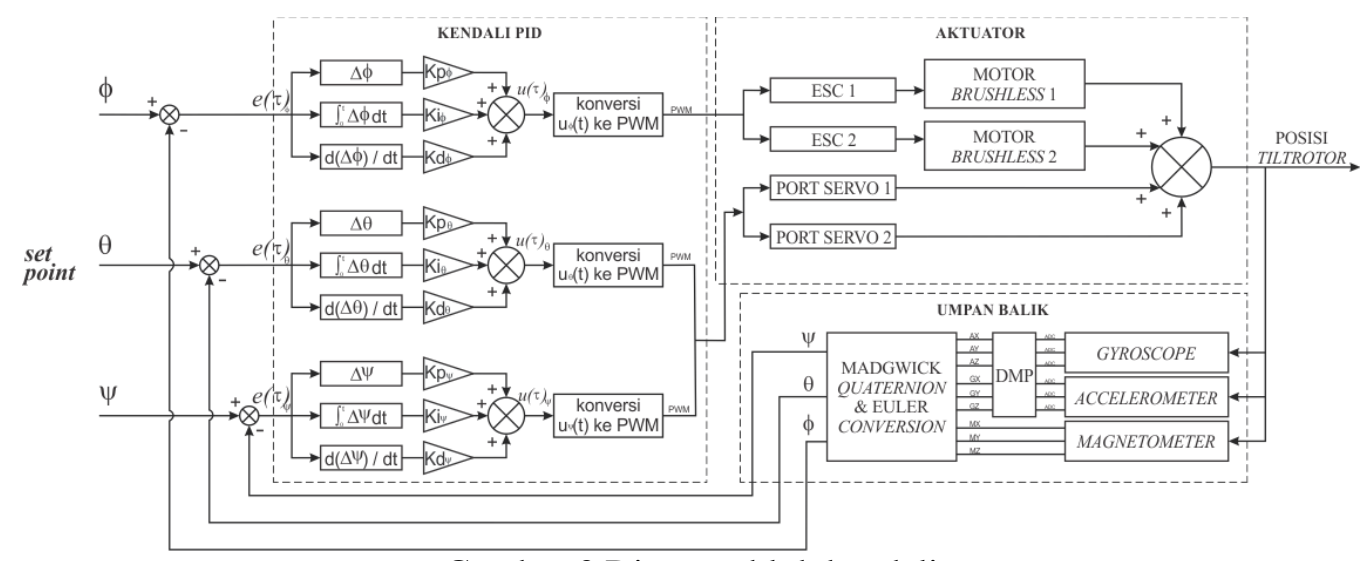

Gambar 3 Diagram blok kendali

IJEIS Vol. 5, No. 2, October 2015 : $199-210$ 


\subsection{Elektronik Sistem}

Rancangan elektronik dari sistem digambarkan secara jelas pada Gambar 4. Pada gambar tersebut terlihat bahwa ESC dan mikrokontroler mendapatkan suplai tegangan sebesar $12 \mathrm{~V}$, $3300 \mathrm{mAh}$ dari power supply sedangkan tegangan yang diperoleh servo adalah $5 \mathrm{~V}$ berasal dari tegangan suplai yang telah diregulasi menggunakan regulator IC7805 sebanyak 2 buah untuk menyediakan arus yang cukup untuk menjalankan servo. Suplai tegangan untuk sensor dan serial komunikasi YS-1020 didapat dari mikrokontroler sebesar 5V.

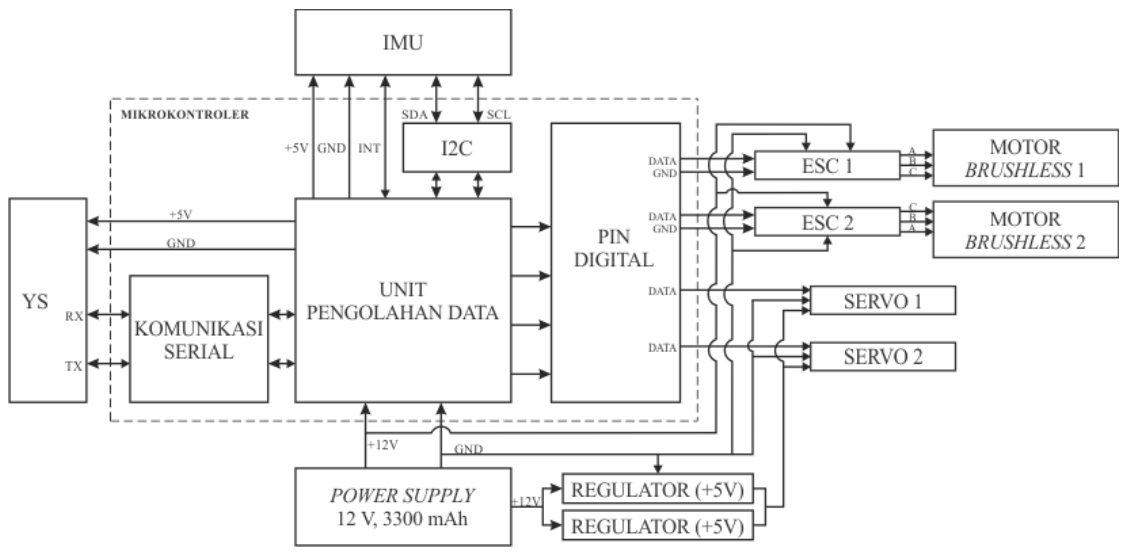

Gambar 4 Diagram blok elektronik sistem

\subsection{Perangkat Lunak Sistem}

Perangkat lunak dalam sistem ini merupakan kumpulan instruksi dan algoritma yang akan dimasukkan ke dalam mikrokontroler. Fungsi perangkat lunak adalah untuk mengakses sensor, aktuator, dan perangkat lainnya yang terdapat dalam sistem. Perangkat lunak yang akan digunakan dalam sistem menggunakan bahasa pemrogram $\mathrm{C}$ dengan compiler Arduino IDE (Integrated Development Environtment) karena mikrokontroler yang digunakan dalam sistem ini adalah Arduino. Gambar 5 merupakan flowchart dari perangkat lunak sistem.

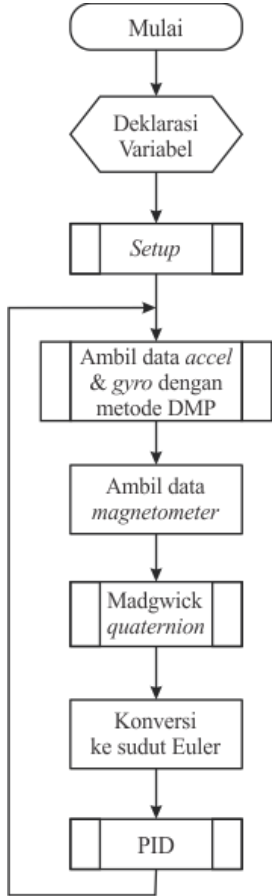

(a)
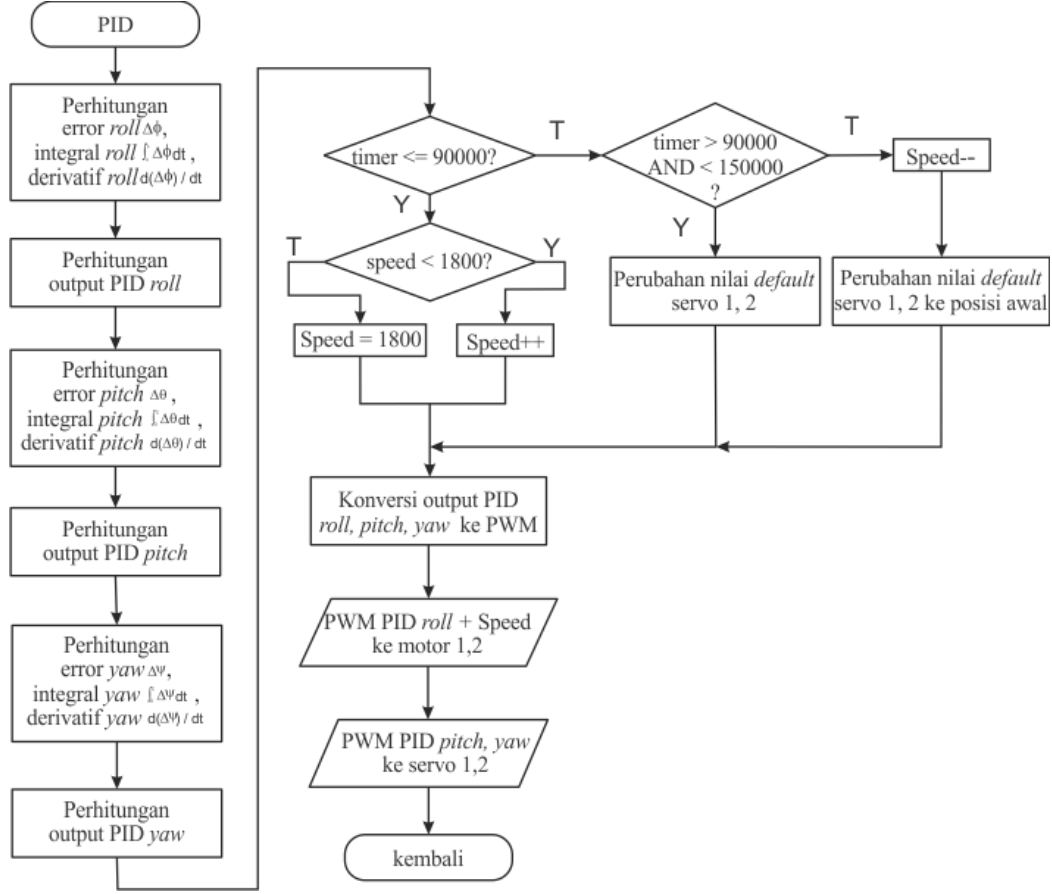

(b)

Gambar 5 Flowchart program (a) utama (b) PID 


\subsection{Perangkat Keras Sistem}

Tiltrotor yang dibuat dalam penelitian ini memiliki 2 buah baling-baling dengan bagian hidung tiltrotor memiliki bentuk kotak dan memiliki ekor sebagai penyeimbang yang tampak pada Gambar 6(a). Tiltrotor yang diimplementasikan memiliki panjang keseluruhan terukur dari hidung hingga ekor $50 \mathrm{~cm}$, lebar $47 \mathrm{~cm}$, dan tinggi terhitung dari kaki hingga baling-baling tiltrotor $16 \mathrm{~cm}$. Rancangan mekanik untuk integrasi servo dengan motor brushless menggunakan Single-Axis OAT (sOAT) tampak pada Gambar 6(b). Dalam sOAT, baling-baling pada tiltrotor memiliki posisi yang tetap dan condong terhadap sumbu horizontal dengan sudut tetap sebesar $\lambda$ dari arah longitudinal [3].

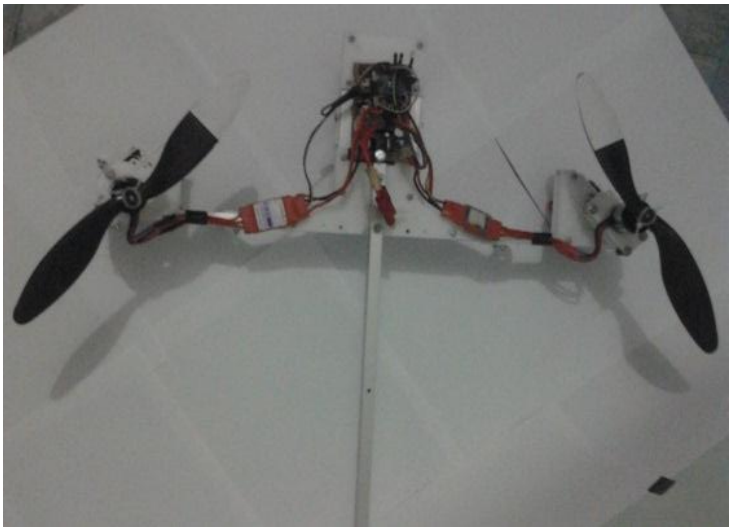

(a)

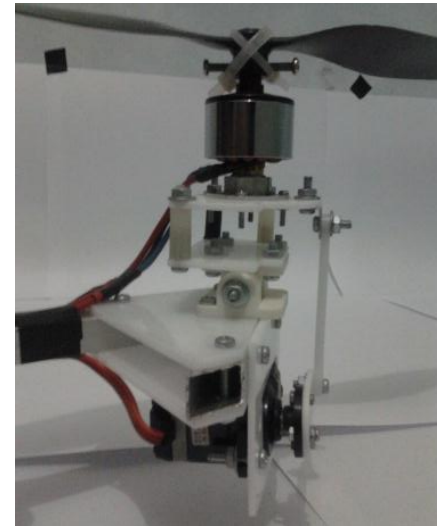

(b)

Gambar 6 Mekanik sistem (a) tiltrotor (b) integrasi motor servo

\section{HASIL DAN PEMBAHASAN}

\subsection{Pengujian Sudut Orientasi Tiltrotor pada Tuning Sistem Kendali}

Tiltrotor memiliki 3 sudut orientasi yaitu sudut roll $(\phi)$, pitch $(\theta)$, dan yaw $(\psi)$. Ketiga sudut ini berisikan informasi mengenai dinamika terbang tiltrotor. Oleh karena itu, sistem kendali yang akan diterapkan pada tiltrotor akan berbeda karakteristiknya pada masing-masing sudut orientasi sehingga tuning perlu dilakukan pada masing-masing sudut orientasi. Metode tuning yang akan digunakan adalah classical tuning Ziegler-Nichols metode osilasi. Dengan metode tuning ini, dapat dihasilkan suatu nilai yang disebut dengan ultimate gain $(\mathrm{Ku})$ dan periode osilasi $(\mathrm{Pu})$.

Tuning dilakukan dengan menggantung tiltrotor pada suatu tiang statis di ruang tertutup sehingga pengaruh angin tidak diperhitungkan dalam sistem ini. Untuk mendapatkan nilai $\mathrm{Ku}$ dan $\mathrm{Pu}$, diberikan nilai 0 pada konstanta $\mathrm{Ki}$ dan $\mathrm{Kd}$ kemudian diberikan variasi nilai pada konstanta Kp hingga sistem dapat berosilasi secara tetap/konstan.

3.1.1 Penentuan nilai Ku dan Pu pada sudut roll

Nilai $\mathrm{Ku}$ yang dipilih untuk sistem kendali adalah $\mathrm{Ku}=0.96$ karena menghasilkan osilasi yang relatif stabil ditunjukkan pada Gambar 7.

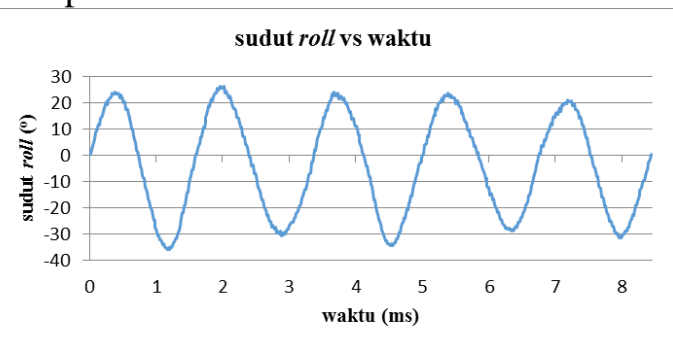

Gambar 7 Grafik sudut roll vs waktu dengan $\mathrm{Ku}=0.96$ 
Pemilihan $\mathrm{Ku}$ harus menghasilkan osilasi yang relatif stabil karena jika sistem tidak menghasilkan osilasi yang stabil maka persamaan yang digunakan untuk metode ZieglerNichols tidak berlaku untuk sistem tersebut dan akan menghasilkan osilasi atau overshoot pada sistem [4]. Terdapat 4 puncak acuan pertama yang digunakan untuk menentukan Pu. Rata-rata periode dari 3 data periode antar puncak tersebut kemudian yang menjadi nilai Pu sistem yang bernilai 1.683 .

\subsubsection{Penentuan nilai Ku dan Pu pada sudut pitch}

Nilai $\mathrm{Ku}$ yang dipilih untuk sistem kendali adalah $\mathrm{Ku}=4.50$ karena menghasilkan osilasi yang relatif stabil ditunjukkan pada Gambar 8.

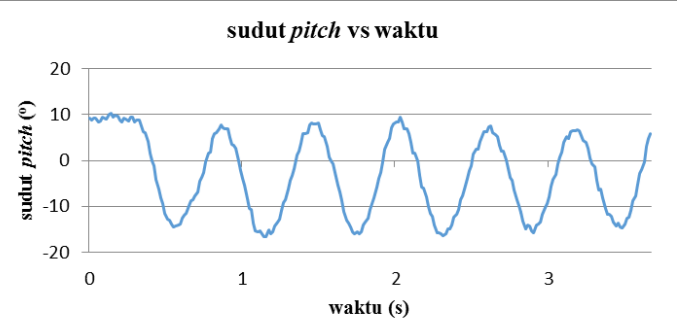

Gambar 8 Grafik sudut pitch vs waktu dengan $\mathrm{Ku}=4.50$

Terdapat 4 puncak acuan pertama yang digunakan untuk menentukan Pu. Rata-rata periode dari 3 data periode antar puncak tersebut kemudian yang menjadi nilai Pu sistem kendali pada sudut pitch yang bernilai 0.593 .

3.1.3 Penentuan nilai Ku dan Pu pada sudut yaw

Nilai $\mathrm{Ku}$ yang dipilih untuk sistem kendali adalah $\mathrm{Ku}=4.80$ karena menghasilkan osilasi yang relatif stabil ditunjukkan pada Gambar 9.

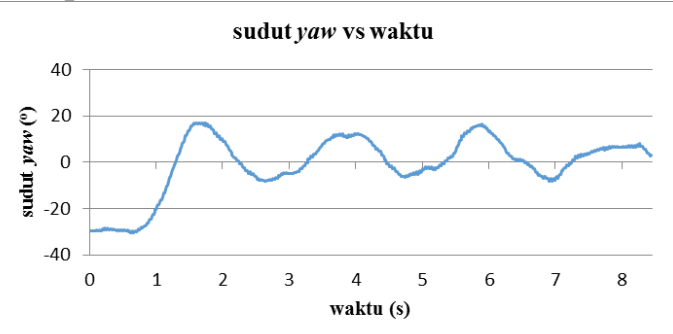

Gambar 9 Grafik sudut yaw vs waktu dengan $\mathrm{Ku}=4.80$

Terdapat 3 puncak acuan pertama yang digunakan untuk menentukan $\mathrm{Pu}$. Rata-rata periode dari 2 data periode antar puncak tersebut kemudian yang menjadi nilai Pu sistem kendali pada sudut yaw yang bernilai 2.612 .

\subsection{Pengujian Sistem Kendali pada Modus Hovering}

Modus hovering merupakan suatu keadaan dimana tiltrotor lepas landas kemudian melayang. Oleh karena itu, setpoint dari sudut orientasi roll dan pitch pada modus ini adalah $0^{0}$. Modus ini sangat mempengaruhi modus selanjutnya yaitu modus transisi. Jika pada modus hovering sistem kendali tidak dapat menyeimbangkan tiltrotor, maka tiltrotor juga akan sulit untuk seimbang ketika tiltrotor dalam modus transisi.

Pengujian juga mencakup kecepatan respon sistem kendali pada sistem. Pengujian kecepatan respon bertujuan untuk mengetahui seberapa cepat respon kendali untuk mengembalikan tiltrotor pada posisi semula atau dalam keadaan tunak (steady state) ketika terdapat gangguan atau perubahan posisi pada suatu sudut orientasi tiltrotor.

3.2.1 Pengujian sistem kendali pada sudut roll modus hovering

Pengujian tiltrotor pada modus hovering dibagi menjadi 3 yaitu pengujian sistem kendali $\mathrm{P}$, pengujian sistem kendali PI, dan pengujian sistem kendali PID menggunakan $\mathrm{Ku}=0.96$ dan $\mathrm{Pu}=1.683$.

Penentuan konstanta P, I, dan D yang akan digunakan dalam pengujian sistem kendali PID pada sudut roll modus hovering tiltrotor adalah sebagai berikut.

$$
K_{p}=0.65 \times K_{u}=0.650 \times 0.960=0.576
$$




$$
\begin{gathered}
K_{i}=\frac{K_{p}}{0.5 \times P_{u}}=\frac{0.576}{0.500 \times 1.683}=0.684 \\
K_{d}=0.075 \times K_{u} \times P_{u}=0.075 \times 0.960 \times 1.683=0.121
\end{gathered}
$$

Hasil pengujian sistem kendali PID pada sudut roll ditampilkan pada Gambar 10(a). Terlihat pada Grafik 10(a) bahwa pada hasil pengujian masih terdapat overshoot. Dengan besarnya overshoot pada sistem kendali maka nilai $K_{i}$ perlu dikurangi. Selain itu, nilai $K_{p}$ juga dikurangi untuk mengurangi osilasi sistem sementara nilai $K_{d}$ ditambah dengan tujuan selain mengurangi overshoot juga meningkatkan stabilitas sistem yang ditampilkan pada Gambar 10(b).

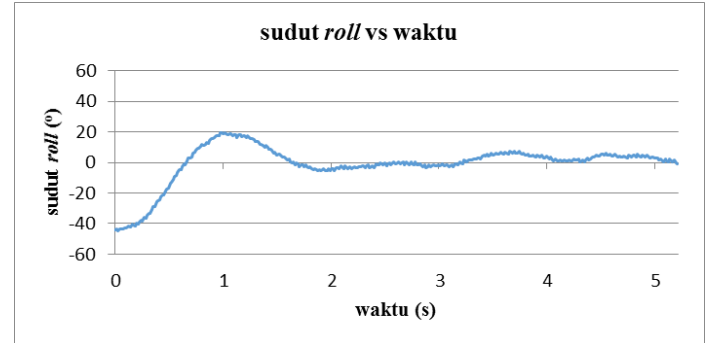

(a)

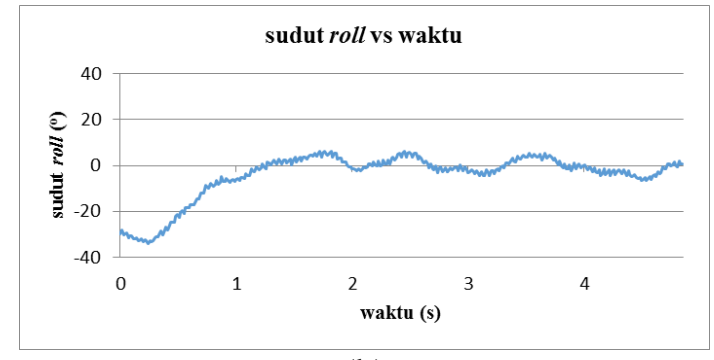

(b)

Gambar 10 Grafik sudut roll vs waktu sistem kendali PID dengan (a) $K_{p}=0.576, K_{\bar{i}}=0.684$, dan $K_{d}=0.121$ (b) $K_{p}=0.526, K_{i}=0.068$, dan $K_{d i}=0.847$

Dilihat dari Gambar 10(b), sistem kendali PID yang diujikan terlihat lebih baik dengan pengurangan overshoot dari sistem. Selain itu, sistem memiliki kestabilan yang relatif tinggi dan sistem kendali meampu menjaga keadaan tunak tiltrotor. Perhitungan rise time diawali dengan mencari nilai konstanta waktu. Konstanta waktu $(\tau)$ merupakan waktu yang ditempuh oleh sistem untuk mencapai 63,2\% menuju setpoint [4]. Caranya adalah dengan memplot karateristik respon sistem yang ditampilkan pada Gambar 11.

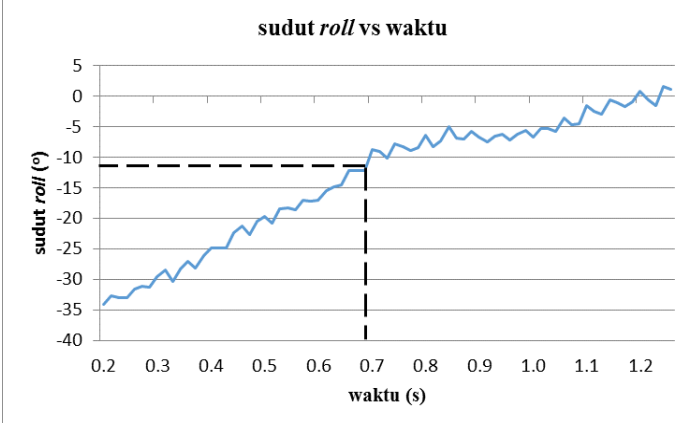

Gambar 11 Grafik sudut roll vs waktu untuk penetuan rise time

Simpangan yang diberikan pada sistem sebesar -34.15 sehingga konstanta waktu dihitung dari -34.15 hingga -12.57 . Waktu tempuhnya yaitu sebesar $0.455 \mathrm{~s}(0.697 s-0.242 s)$. Dengan konstanta waktu yang telah ditentukan maka rise time juga dapat ditentukan.

$$
\text { tr }=\tau \times 2.20=0.455 \times 2.20=1.00 \mathrm{~s}
$$

Waktu tempuh sebesar $1.00 \mathrm{~s}$ untuk sistem kendali pada sudut roll sudah dapat dinyatakan baik namun dapat diotimalkan lagi dengan mengganti motor brushless dengan daya angkat yang tinggi dikarenakan daya angkat tiltrotor hanya dipengaruhi oleh 2 buah motor brushless.

3.2.2 Pengujian sistem kendali pada sudut pitch modus hovering

Pengujian tiltrotor pada modus hovering dibagi menjadi 3 yaitu pengujian sistem kendali $\mathrm{P}$, pengujian sistem kendali PI, dan pengujian sistem kendali PID menggunakan $\mathrm{Ku}=0.96$ dan $\mathrm{Pu}=1.683$.

Penentuan konstanta P, I, dan D yang akan digunakan dalam pengujian sistem kendali PID pada sudut pitch modus hovering tiltrotor adalah sebagai berikut.

$$
\begin{gathered}
K_{p}=0.65 \times K_{u}=0.650 \times 4.500=2.700 \\
K_{i}=\frac{K_{p}}{0.5 \times P_{u}}=\frac{2.700}{0.500 \times 0.593}=2.277
\end{gathered}
$$




$$
K_{d}=0.075 \times K_{u} \times P_{u}=0.075 \times 4.500 \times 0.593=0.200
$$

Hasil pengujian sistem kendali PID pada sudut pitch ditampilkan pada Gambar 12(a). Gambar 12(a) menunjukkan bahwa penerapan sistem kendali PID memiliki overshoot yang tinggi. Overshoot bernilai kurang lebih sebesar $-20^{\circ}$ dengan simpangan sebesar $24^{\circ}$. Namun, kelebihan dari sistem kendali PID adalah sistem dapat mengurangi steady state error atau dengan kata lain sistem kendali mampu menjaga sudut pitch tiltrotor pada $0^{\circ}$. Untuk mengurangi overshoot maka nilai Kp dan Ki perlu dikurangi. Pengujian selanjutnya menggunakan konstanta Kp dan Ki yang telah dikurangi yang secara berurutan bernilai 2.600 dan 0.017 . Hasil pengujian ditampilkan pada Gambar 12(b).

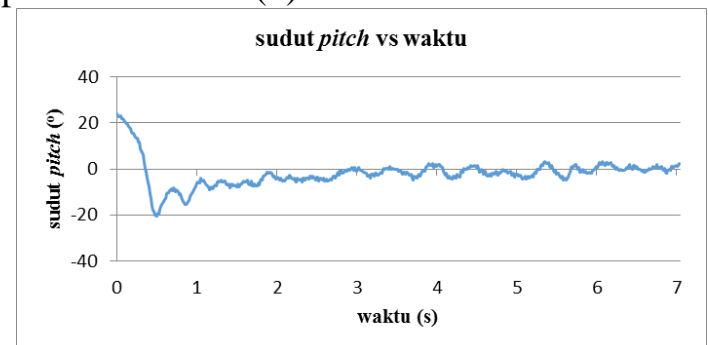

(a)

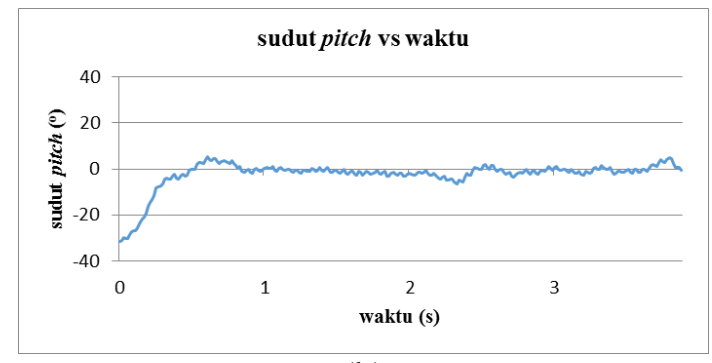

(b)

Gambar 12 Grafik sudut pitch vs waktu sistem kendali PID dengan (a) $K_{p}=2.700, K_{i}=2.277$, dan $K_{d}=0.200$ (b) $K_{p}=2.600, K_{i}=0.017$, dan $K_{d}=0.200$

Terbukti dengan pengurangan $\mathrm{Kp}$ dan $\mathrm{Ki}$ dapat mengurangi overshoot. Dengan tetap menjaga nilai $\mathrm{Kd}$ maka steady state error dapat juga dikurangi dengan respon yang hampir sama dengan pengujian sebelumnya. Sistem kendali mampu meredam overshoot dan dapat menjaga kestabilan sistem.

Plot grafik penentuan titik ke $63.2 \%$ ditampilkan pada Gambar 13. Simpangan pada sistem adalah sebesar $-31.74^{\circ}$ sehingga titik $63.2 \%$ terhitung dari simpangan adalah sebesar $-11.68^{\circ}$.

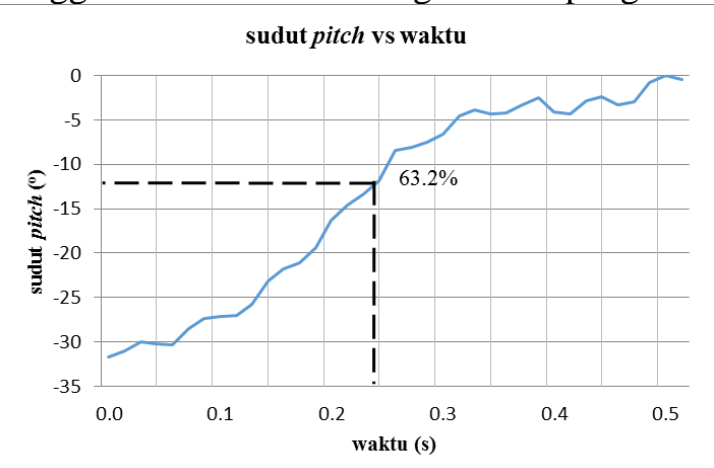

Gambar 13 Grafik sudut pitch vs waktu untuk penetuan rise time

Waktu yang dibutuhkan adalah sebesar 0.242 sekon sehingga perhitungan rise time adalah sebagai berikut.

$$
t r=\tau \times 2.2=0.242 \times 2.2=0.532 \mathrm{~s}
$$

Dengan nilai $t r=0.532 \mathrm{~s}$ maka dapat dinyatakan bahwa rise time sistem kendali pada sudut pitch relatif cepat. Hal ini membuktikan bahwa mekanika sistem pitching menggunkan sistem OAT memiliki efektifitas yang tinggi untuk pitching tiltrotor.

3.2.3 Pengujian sistem kendali pada sudut yaw modus hovering

Penentuan konstanta P, I, dan D yang akan digunakan dalam pengujian sistem kendali PID pada sudut yaw modus hovering tiltrotor dituliskan pada persamaan berikut.

$$
\begin{gathered}
K_{p}=0.65 \times K_{u}=0.650 \times 4.800=2.880 \\
K_{i}=\frac{K_{p}}{0.5 \times P_{u}}=\frac{2.880}{0.500 \times 2.162}=2.664 \\
K_{d}=0.075 \times K_{u} \times P_{u}=0.075 \times 4.800 \times 2.162=0.778
\end{gathered}
$$

Hasil pengujian kendali PID pada sudut yaw ditampilkan pada Gambar 14(a). Sistem kendali menggunakan perhitungan masih menimbulkan osilasi sistem yang semakin kuat seiring 
bertabahnya waktu. Pengurangan osilasi dapat dilakukan dengan mengurangi nilai Kp dan Ki. Pengujian kemudian dilanjutkan dengan mengubah nilai Kp menjadi 1.440 dan $\mathrm{Ki}=0.027(1 \%)$ sementara Kd tetap. Hasli pengujian ditampilkan pada Gambar 14(b). Sudut rata-rata hasil pengujian tersebut adalah sebesar $-3.78^{\circ}$ dengan standar deviasi $1.83^{\circ}$. Pada grafik tersebut menunjukkan kestabilan yang relatif baik sehingga dapat digunakan untuk mempertahankan sudut yaw pada tiltrotor.

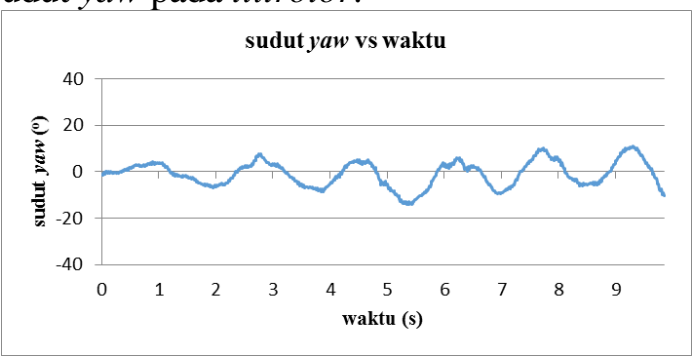

(a)

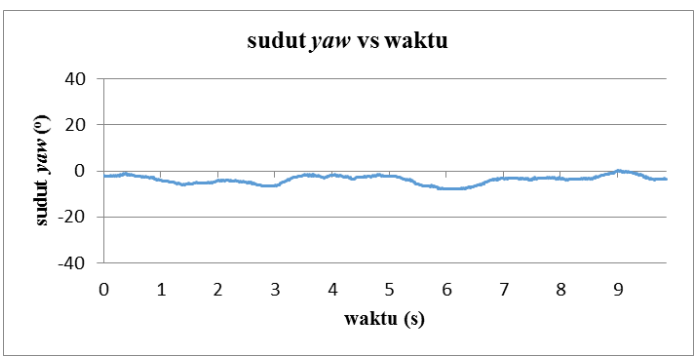

(b)

Gambar 14 Grafik sudut yaw vs waktu sistem kendali PID dengan (a) $K_{p}=2.880, K_{i}=2.664$, dan $K_{\mathbb{d}}=0.778$ (b) $K_{p}=1.440, K_{i}=0.027$, dan $K_{\mathbb{d}}=0.778$

\subsection{Pengujian Sistem Kendali pada Modus Transisi}

Pengujian sistem kendali pada modus transisi menggunakan sistem kendali terbaik yang didapatkan pada pengujian sistem kendali pada modus hovering tiltrotor. Pengujian sistem kendali pada modus transisi juga akan dilakukan pada sudut orientasi roll dan pitch.

Modus transisi merupakan suatu keadaan dimana tiltrotor berganti dari modus hovering menjadi modus terbang. Dalam modus transisi ini terjadi pergerakan servo yang semula tegak lurus dengan tiltrotor menjadi condong ke depan. Hal ini dilakukan agar tiltrotor dapat terbang maju pada modus terbang. Perubahan sudut servo pada modus transisi adalah sebesar $20^{\circ}$. Dengan perubahan posisi sudut servo dan untuk menghasilkan pergerakan terbang maju pesawat maka setpoint sudut pitch pada tiltrotor perlu diubah. Perubahan setpoint sudut pitch yang semula $0^{\circ}$ pada modus hovering menjadi sebesar $-25^{\circ}$ pada modus transisi. Dengan berubahnya derajat baling-baling pada tiltrotor maka daya dorong juga akan menurun dikarenakan dorongan tidak searah dengan gaya berat tiltrotor. Oleh karena itu, diperlukan penambahan kecepatan putar baling-baling pada modus transisi.

\subsubsection{Pengujian sistem kendali pada sudut roll modus transisi}

Sistem kendali yang akan digunakan pada pengujian sudut roll modus transisi adalah sistem kendali PID dengan $K_{p}=0.526, K_{i}=0.068$, dan $K_{d}=0.847$. Sistem kendali PID tersebut merupakan sistem kendali terbaik pada pengujian sistem kendali pada sudut roll modus hovering. Hasil pengujian sistem kendali pada sudut roll modus transisi ditampilkan pada Gambar 15.

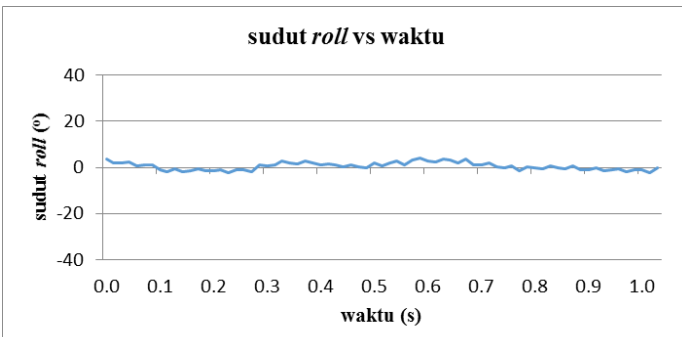

Gambar 15 Grafik sudut roll vs waktu pada modus transisi

Rata-rata sudut roll yang dihasilkan dari grafik pada Gambar 15 adalah sebesar $0.48^{\circ}$ dengan standar deviasi sebesar $1.75^{\circ}$ (data lengkap disajikan pada Lampiran). Hasil pengujian ini membuktikan bahwa pada sudut roll, sistem kendali PID yang digunakan pada modus hovering juga mampu menghasilkan kestabilan sistem secara efektif pada modus transisi. 3.3.2 Pengujian sistem kendali pada sudut pitch modus transisi 
Sistem kendali yang akan digunakan pada pengujian sudut pitch modus transisi adalah sistem kendali PID dengan $K_{p}=2.600, K_{i}=0.017$, dan $K_{d}=0.200$. Sistem kendali PID tersebut merupakan sistem kendali terbaik pada pengujian sistem kendali pada sudut pitch modus hovering. Hasil pengujian sistem kendali pada sudut pitch modus transisi ditampilkan pada Gambar 16.

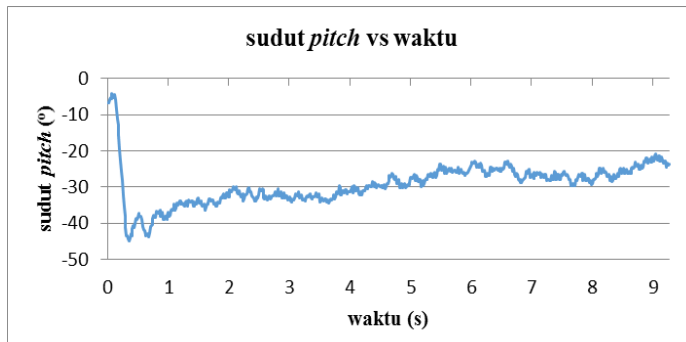

Gambar 16 Grafik sudut pitch vs waktu pada modus transisi dengan $K_{p}=2.600, K_{i}=0.017$, dan

$$
K_{d}=0.200
$$

Terlihat bahwa pada grafik Gambar 16, analisis data tidak dapat dilakukan pada 1 detik saja. Sistem kendali dapat mengembalikan tiltrotor pada setpoint $\left(25^{\circ}\right)$ setelah detik ke-5. Hal ini tentunya akan mengakibatkan sistem menjadi tidak stabil dengan respon yang sangat lambat. Kasus seperti ini diakibatkan karena pergerakan motor servo sangat berpengaruh terhadap sudut pitch tiltrotor. Hal inilah yang menyebabkan terjadinya simpangan sudut pitch yang cukup besar ketika tiltrotor memasuki modus transisi. Untuk menanggulangi hal tersebut diperlukan sistem kendali yang lebih responsif agar tiltrotor dapat kembali ke setpoint dengan lebih cepat.

Untuk mendapatkan sistem kendali, cara yang digunakan adalah dengan metode osilasi Ziegler-Nichols pada sudut pitch mode transisi. Didapat nilai Ku sebesar 9.50 dengan metode osilasi pada sudut pitch modus transisi. Hasil pengujian nilai $\mathrm{Ku}=9.50$ pada sudut pitch ditampilkan pada Gambar 17(a).

$\mathrm{Ku}$ dengan nilai 9.50 menunjukkan bahwa osilasi yang dihasilkan sistem relatif stabil sehingga nilai $\mathrm{Ku}$ tersebut digunakan untuk penentuan konstanta $\mathrm{P}, \mathrm{I}$, dan D. Sistem kendali yang akan digunakan adalah sistem kendali PID karena pada pengujian-pengujian yang telah dilakukan sebelumnya membuktikan bahwa PID lebih baik dibandingkan sistem kendali $\mathrm{P}$ maupun PI. Nilai Pu didapat dari rata-rata periode osilasi dari puncak ke puncak. Terdapat 4 puncak acuan yang akan dijadikan acuan pada perhitungan $\mathrm{Pu}$. Pu1 bernilai 0.469 , Pu2 bernilai 0.339 , dan Pu3 bernilai 0.441 sehingga rata-ratanya bernilai 0.327 yang menjadi nilai Pu.

$\mathrm{Ku}$ dengan nilai 9.50 dan $\mathrm{Pu}$ dengan nilai 0.327 menghasilkan konstanta $\mathrm{P}$ sebesar 5.7, konstanta I sebesar 34.862, konstanta D sebesar 0.233. Namun, dengan perhitungan ZieglerNichols menghasilkan nilai Ki yang sangat besar. Nilai Ki yang besar ini dapat meningkatkan overshoot sehingga dalam pengujian sistem kendali nilai Ki diturunkan secara drastis hingga menjadi $0.349(1 \%)$. Hasil pengujian ditampilkan pada Gambar 17(b).

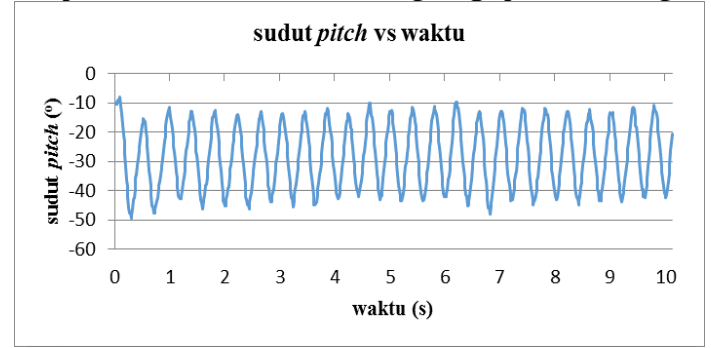

(a)

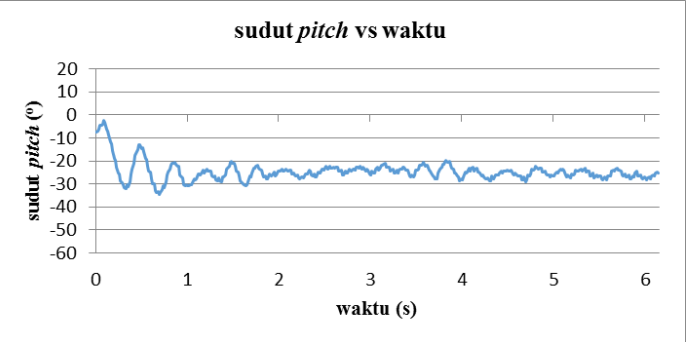

(b)

Gambar 17 Grafik sudut pitch vs waktu (a) tuning dengan $\mathrm{Ku}=9.50$ (b) sistem kendali PID dengan $K_{p}=5.700, K_{i}=0.349$, dan $K_{d i}=0.233$

Dapat terlihat pada Gambar 17(b) bahwa sudut kendali mampu mengembalikan tiltrotor ke setpoint pada modus transisi. Steady-state error juga mampu diredam dengan menggunakan sistem kendali ini meskipun overshoot tetap muncul dalam respon sistem. Kemudian dari hasil 
pengujian tersebut ditentukan rata-rata dan standar deviasi. Rata-rata dan standar deviasi dihitung dari titik pertama yang mencapai $-25^{\circ}$ hingga data terakhir pada grafik. Titik pertama yang mencapai $-25^{\circ}$ ketika waktu transisi mencapai $0.242 \mathrm{~s}$. Data hasil pengujian disajikan pada lampiran. Rata-rata sudut pitch adalah sebesar $-25.26^{\circ}$ dengan standar deviasi $2.87^{\circ}$. Dengan melihat hasil pengujian tersebut maka dapat dinyatakan bahwa sistem kendali yang cocok untuk sudut pitch modus transisi tiltrotor adalah sistem kendali PID dengan $K_{p}=5.700, K_{i}=0.349$, dan $K_{d}=0.233$. Sistem kendali ini mampu mempertahankan posisi sudut pitch pada $-25^{\circ}$ ketika tiltrotor memasuki modus transisi.

\section{KESIMPULAN}

Dari hasil pengamatan, pengujian, dan analisis pada hasil yang diperoleh dalam penelitian ini, kesimpulan yang dapat diambil adalah sebagai berikut:

1. Telah dirancang dan dibuat sistem kendali untuk menjaga kestabilan sudut orientasi roll, pitch, dan yaw tiltrotor pada modus hovering dan transisi menggunakan PID.

2. Sistem kendali pada modus transisi pada sudut roll dengan setpoint $0^{\circ}$ mampu mempertahankan posisi sudut roll pada sudut rata-rata $0.48^{\circ}$ dengan standar deviasi $1.75^{\circ}$, pada sudut pitch dengan setpoint $-25^{\circ}$ mampu mempertahankan posisi sudut pitch pada sudut rata-rata $-25.26^{\circ}$ dengan standar deviasi $2.87^{\circ}$, pada sudut yaw mampu mempertahankan posisi sudut yaw pada rentang $-10^{\circ}$ hingga $0^{\circ}$ dengan sudut rata-rata $-3.78^{\circ}$ dan standar deviasi $1.83^{\circ}$.

\section{SARAN}

Pada penelitian ini masih terdapat banyak kekurangan sehingga perlu dilakukan penyempurnaan. Berikut saran-saran untuk semakin menyempurnakan penelitian ini.

1. Peran aktuator pada tiltrotor sangat berpengaruh besar terhadap sistem kestabilan tiltrotor sehingga perlu perhatian penuh pada pemilihan spesifikasi aktuator. Misalnya menggunakan motor brushless dengan thrust yang besar sehingga dapat mempercepat respon sistem kendali.

2. Diperlukan metode tuning yang lebih baik pada sudut yaw agar didapat sistem kendali yang akurat dan mampu mempertahankan sudut yaw tiltrotor dengan baik. Untuk penelitian selanjutnya, mekanika sistem tilting pada tiltrotor dapat ditingkatkan kemampuannya dengan menggunakan dual oblique active tilting yang dapat mengurangi interferensi sistem kendali pada sudut pitch terhadap perilaku perubahan sudut motor servo pada modus transisi sehingga tiltrotor dapat menghasilkan perilaku terbang maju secara maksimal.

\section{DAFTAR PUSTAKA}

[1] Ogata, K., 2010, Modern Conrol Engineering Fifth Edition, Prentice Hall, New Jersey.

[2] Copeland, B.R., 2008, The Design of PID Controllers Using Ziegler Nichols Tuning. New York.

[3] Gress, G.R., 2007, Lift fans as Gyroscopes for Controlling Compact VTOL Air Vehicles: Overview and Development Status of Oblique Active Tilting. Gress Aerospace, Toronto, Canada.

[4] Kardono, Effendi, R.A.K., Fatoni, A., 2012, Perancangan dan Implementasi Sistem Pengaturan Optimal LQR untuk Menjaga Kestabilan Hover pada Quadcopte, Jurnal Teknik ITS Vol.1.

IJEIS Vol. 5, No. 2, October 2015 : 199 - 210 